\title{
O JOGO DA CATAPULTA PARA COMPREENDER O PLANEJAMENTO E ANÁLISE DE EXPERIMENTOS: PROPOSTA DE UMA ABORDAGEM LÚDICA DE ENSINO
}

\section{THE GAME OF CATAPULT TO UNDERSTAND THE DESIGN OF EXPERIMENTS: ONE PROPOSAL OF PLAYFUL APPROACH FOR TEACHING}

\author{
Noel Torres Júnior * E-mail: noel@face.ufmg.br \\ Roberto da Costa Quinino** E-mail: roberto@est.ufmg.br \\ *Faculdade de Ciências Econômicas (UFMG), Belo Horizonte, MG \\ ${ }^{* *}$ Instituto de Ciências Exatas (UFMG), Belo Horizonte, MG
}

Resumo: Este trabalho propõe o uso do Jogo da Catapulta para o ensino de técnicas de planejamento e análise de experimentos. Este jogo consiste numa simples Catapulta capaz de lançar pequenos objetos. A mesma pode sofrer diferentes ajustes, uma vez que até cinco variáveis de controle podem ser alteradas. A possibilidade de introduzir diferentes ajustes na catapulta permite a condução de diversos tipos de tratamentos e a aplicação de diversas técnicas de planejamento de experimentos. Nesta direção, um experimento fatorial $2^{\mathrm{k}}$ foi realizado e é apresentado. Além disto, o texto aborda o DOE (Design of Experiments) por meio da Regressão Linear Múltipla com o uso do Coeficiente de Determinação $\mathrm{R}^{2}$ como medida de avaliação da significância dos fatores e da interação entre eles. Apesar da simplicidade do dispositivo proposto, vários cuidados e atividades existentes na condução de experimentos industriais se fazem presentes neste jogo. Isto por sua vez, possibilita trabalhar de modo lúdico vários conceitos importantes desta técnica.

Palavras-chave: Jogos Educativos. Planejamento e Análise de Experimentos. Coeficiente de Determinação.

Abstract: This paper proposes the use of the Catapult game for teaching design of experiments. This game consists of a small catapult capable of launching small objects. This can have different settings, so up to five control variables can be changed. The possibility of introducing different adjustments to the catapult allows driving of several types of treatments and the use of various DOE techniques. In this direction, one $2^{k}$ factorial experiment was performed and is presented. Moreover, the text addresses the DOE through the Multiple Linear Regression using the regression coefficient $R^{2}$ as a measure for assessing the significance of the factors and the interaction between them. Despite the simplicity of the catapult device, several existing activities in conducting industrial experiments are present in this game. This work provides several important concepts of this technique through play.

Keywords: Educational Games. Design of Experiments. Regression Coefficient.

\section{INTRODUÇÃO}

A busca por maior qualidade e produtividade se faz presente em várias organizações industriais. Decorrência disto, vários programas e ferramentas para gestão da qualidade são implementados (CARVALHO, HOO e PINTO, 2007; 
CARVALHO e PALADINI, 2005). Vários destes programas se apoiam em ferramentas estatísticas utilizadas com o propósito de efetivação de melhorias nos processos e produtos. Dentro deste contexto, as técnicas de planejamento e análise de experimentos (Design of Experiments - DOE) têm merecido grande destaque em diversos programas de qualidade (PINTO; CARVALHO; HOO, 2009; RODRIGUES; WERNER, 2012). Estas são utilizadas para melhorar as características de qualidade dos produtos e processos de produção, reduzir o número de reclamações e melhorar o uso de recursos da empresa (energia, material, tempo dos funcionários, disponibilidade de equipamentos, etc.) (i.e. MELO; CATEN; SANT'ANNA, 2013; VIANA; NETO, 2013; MELLO; FERREIRA, 2014, entre outros). Fruto deste contexto, - DOE passa a ser difundido nas organizações produtivas de maneira intensa (PINTO; CARVALHO; HOO, 2009; RODRIGUES; WERNER, 2012). Muitas das vezes, esta difusão ocorre de maneira mecânica, seguindo uma lógica tradicional de ensino centrada na memorização e na aplicação de fórmulas e no uso intensivo de rotinas padronizadas de comandos de programas computacionais estatísticos (BARRENTINE, 1999; CUPELLO, 1999). Outras vezes, o ensino desta ferramenta privilegia as fórmulas e deduções matemáticas, tornando a compreensão da técnica acessível apenas às pessoas com conhecimento avançado de matemática (BARRENTINE, 1999; GALDAMEZ, 2002; TANCO et al, 2009; CUPELLO, 1999). Como consequência destes processos de ensino, vários conceitos importantes para a correta condução de experimentos como casualização, blocagem, interação e replicação (COSTA; PIRES; RIBEIRO, 2006) não são assimilados de modo satisfatório pelos seus participantes (BARRENTINE, 1999; TANCO et al., 2009).

Como alternativa a essa realidade, o presente trabalho apresenta uma proposta de ensino do DOE apoiada em atividades lúdicas. Esta proposta se assenta no uso do jogo. Este pode ser entendido como:

Jogo é o resultado de interações linguísticas diversas em termos de características e ações lúdicas, ou seja, atividades lúdicas que implicam no prazer, no divertimento, na liberdade e na voluntariedade, que contenham um sistema de regras claras e explícitas e que tenham um lugar delimitado onde possa agir: um espaço ou um brinquedo (SOARES, 2008, p.3). 
O presente trabalho se apoia no uso do jogo de caráter didático. Este apresenta duas grandes funções: uma função lúdica que visa propiciar diversão e prazer, e outra função educativa que consiste em ensinar e levar o indivíduo a reflexão e ao conhecimento. Estas duas funções procuram ser atendidas de modo equilibrado neste texto.

Tendo como referência estas duas funções e baseando-se no trabalho de Mathews (2005), o presente artigo tem como objetivo demonstrar a eficácia de um jogo de caráter didático para o aprendizado da ferramenta $D O E$ em relação aos métodos tradicionais de ensino.

Com este intuito, os autores conceberam uma pequena Catapulta ${ }^{1}$ capaz de lançar pequenos objetos. A mesma pode sofrer diferentes ajustes, uma vez que até cinco variáveis de controle podem ser modificadas. A possibilidade de introduzir diferentes ajustes na catapulta possibilita a condução de diversos tipos de tratamentos e a aplicação de diversas técnicas de planejamento de experimentos. Além disto, baseando-se no trabalho de Quinino, Reis e Bessagato (2013), o texto aborda o DOE por meio da Regressão Linear Múltipla com o uso do Coeficiente de Determinação $\mathrm{R}^{2}$ como medida de avaliação da significância dos fatores e da interação entre eles.

\section{PLANEJAMENTO DE EXPERIMENTOS}

Normalmente, os experimentos planejados são conduzidos de modo sequencial. Isto significa que o primeiro experimento lida com um sistema complexo onde existem muitas variáveis controláveis. Nesta situação, realiza-se um experimento exploratório (screening experiment) que visa determinar quais dessas variáveis são as mais importantes. Os experimentos subsequentes lidam apenas com as variáveis críticas identificadas no experimento anterior. Estes são utilizados para refinar as informações compiladas e determinar quais ajustes são requeridos, de modo a melhorar o processo. Finalmente, num estágio mais avançado de

\footnotetext{
${ }^{1}$ Catapultas são mecanismos de cerco que utilizam uma espécie de braço para lançar um objeto (pedras e outros) a uma grande distância, evitando assim possíveis obstáculos como muralhas e fossos.
} 
experimentação, o objetivo é a otimização, ou seja, determinar quais os níveis resultantes das variáveis críticas que conduzam o processo a um melhor desempenho (MONTGOMERY, 1991; CALADO; MONTGOMERY, 2003; MONTGOMERY; RUNGER, 2009). Muitas ferramentas podem ser utilizadas para este fim. Baseando-se em diversos autores da área de Estatística Industrial, os autores Galdamez e Carpinetti (2004) reportam as principais ferramentas de DOE e estas são apresentadas no Quadro 1.

Quadro 1 - Principais ferramentas de DOE

\begin{tabular}{|c|c|}
\hline Ferramenta & Características \\
\hline Planejamento fatorial & $\begin{array}{l}\text { Utilizada quando todas as combinações dos níveis dos fatores de } \\
\text { controle são realizadas. }\end{array}$ \\
\hline Planejamento fatorial $2^{k}$ & Técnica com dois níveis e $2^{\mathrm{k}}$ número de combinações de $\mathrm{k}$ fatores. \\
\hline $\begin{array}{l}\text { Planejamento fracionado } \\
2^{k-p}\end{array}$ & $\begin{array}{l}\text { Utilizado quando há vários fatores de controle e não é viável } \\
\text { economicamente para as empresas realizar todas as combinações dos } \\
\text { experimentos. }\end{array}$ \\
\hline $\begin{array}{l}\text { Metodologia de superfície } \\
\text { de resposta }\end{array}$ & $\begin{array}{l}\text { Response Surfasse methodology (MSR) é um conjunto de técnicas de } \\
\text { planejamento e análise de experimentos usadas na modelagem } \\
\text { matemática de respostas. Ou seja, procura-se identificar os } \\
\text { relacionamentos existentes entre os parâmetros, representados por } \\
\text { variáveis quantitativas, como tempo, velocidade, pressão, temperatura, } \\
\text { etc., e as respostas do sistema analisado. }\end{array}$ \\
\hline $\begin{array}{l}\text { Planejamento fatorial } 2^{k} \text {, } \\
\text { com pontos centrais }\end{array}$ & $\begin{array}{l}\text { Esse método consiste em adicionar um ponto de experimentação no } \\
\text { nível intermediário aos níveis investigados para os k fatores de controle. } \\
\text { Esta técnica é recomendada para verificar a existência do efeito } \\
\text { curvatura no sistema analisado. }\end{array}$ \\
\hline \multirow[t]{3}{*}{ Gráficos } & $\begin{array}{l}\text { Os gráficos de efeitos principais ilustram a variação média das respostas } \\
\text { em função da mudança no nível de um fator, mantendo os outros fatores } \\
\text { constantes. }\end{array}$ \\
\hline & $\begin{array}{l}\text { Os gráficos de efeitos de interação descrevem a variação média de um } \\
\text { fator em função dos níveis de outros fatores. }\end{array}$ \\
\hline & $\begin{array}{l}\text { O gráfico de probabilidade normal é utilizado nas situações em que não é } \\
\text { possível repetir um experimento e é importante obter uma estimativa } \\
\text { independente do erro experimental para julgar a importância dos efeitos } \\
\text { principais e de interação. }\end{array}$ \\
\hline
\end{tabular}

Fonte: Quadro 1 de Galdamez e Carpinetti (2004). 


\subsection{Ferramentas utilizadas}

As ferramentas estatísticas abordadas neste trabalho foram definidas levando-se em consideração algumas restrições existentes para o ensino desta técnica em cursos desta natureza e o grau de utilização da ferramenta em experimentos industriais. Nesta direção, restrições como carga horária disponível em disciplinas introdutórias de $D O E$ e a complexidade de certas técnicas direcionaram a escolha dos tipos de experimentos abordados neste trabalho. Considerando esses aspectos, os autores discutem apenas os experimentos fatoriais $2^{\mathrm{k}}$.

\subsection{0 uso da regressão em experimentos fatoriais $2^{k}$}

Os planejamentos fatoriais $2^{k}$ podem ser analisados por meio de Modelos Lineares Gerais (General Linear Models). Nesta direção, os autores Mathews (2005), Barrentine (1999) e Mendenhall e Sincich (2012) apresentam esta abordagem quando explicam experimentos deste tipo. O uso da regressão pode ser visto como uma alternativa didática para o ensino de $D O E$, uma vez que a regressão trabalha com o conceito de variável dependente (correspondente à variável resposta para o $D O E$ ) e as variáveis independentes (correspondentes aos fatores controlados). Além disso, as relações entre possíveis causas e o efeito tornam-se mais claras nos modelos de regressão. Soma a estes aspectos, o fato de que, normalmente, os estudantes da graduação e profissionais da indústria já estão familiarizados com esta ferramenta estatística.

A seleção de um modelo de regressão deve ser feita de maneira a escolher as variáveis que sejam significativas para o modelo. Para tanto, o método dos melhores subconjuntos pode ser utilizado. O mesmo consiste na avaliação de todos os possíveis modelos de regressão para determinar o conjunto de variáveis independentes que formará o modelo final (LEVINE et al., 2011). Este método pode ser feito utilizando o Teste $F_{\text {parcial }}$. O mesmo é descrito a seguir. 
A escolha de novas variáveis independentes para o modelo de regressão pode ser feita comparando-se dois modelos aninhados (Nested Models). Dois modelos são considerados aninhados se um modelo contém todos os termos do segundo modelo e pelo menos um termo adicional. O modelo com mais termos é denominado de modelo completo ou integral e o mais simples é chamado de modelo reduzido ou restrito (MENDENHALL; SINCICH, 2012).

No desenvolvimento de um modelo de regressão múltipla, somente aquelas variáveis independentes que reduzam significativamente o erro ao prever o valor de uma variável dependente devem ser utilizadas. Portanto, se uma variável independente não melhorar essa previsão, esta pode ser excluída do modelo (LEVINE et al., 2011).

O teste $F_{\text {parcial }}$ é um método alternativo para determinar a contribuição de uma variável independente em um modelo. Esse método envolve a avaliação da contribuição dada por cada nova variável independente para a soma dos quadrados da regressão, depois que todas as outras variáveis independentes foram incluídas no modelo. Neste teste a nova variável independente só é incluída no modelo se aperfeiçoar significativamente o mesmo (LEVINE et al., 2011).

De acordo com Mendenhall e Sincich (2012) e Dielman (2005), neste teste a hipótese nula e a hipótese alternativa são construídas para testar a contribuição da(s) variável(is) $\beta_{g+1}, \beta_{g+2} \ldots \beta_{k}$ para o modelo.

Modelo Completo: $E(y)=\beta_{0}+\beta_{1} X_{1}+\cdots+\beta_{g} X_{g}$

$\beta_{g+1} X_{g+1}+\cdots+\beta_{k} X_{k}$

Modelo Reduzido: $E(y)=\beta_{0}+\beta_{1} X_{1}+\cdots+\beta_{g} X_{g}$

- $H_{0}: \beta_{g+1}=\beta_{g+2}=\cdots=\beta_{k}=0$ (As variáveis adicionadas não aperfeiçoam significativamente o modelo).

- $H_{1}: \beta_{g+1} \neq \beta_{g+2} \neq \cdots \neq \beta_{k} \neq 0$ (Pelo menos uma das variáveis é diferente de zero, portanto essas variáveis aperfeiçoam significativamente o modelo). 
De acordo com Quinino, Reis e Bessagato (2013), o Teste $F_{\text {parcial }}$ pode ser calculado utilizando- se o Coeficiente de Determinação, conforme fórmula a seguir:

$F_{\text {parcial }}=\frac{\left(R_{c}^{2}-R_{r}^{2}\right) /(k-g)}{\left(1-R_{c}^{2}\right) /(n-(k+1)]}$.

Onde:

- $\quad R_{r}^{2}=$ Coeficiente de Determinação $R^{2}$ do modelo reduzido

- $R_{c}{ }^{2}=$ Coeficiente de Determinação $R^{2}$ do modelo completo

- $\quad k+1=$ Número de parâmetros no modelo completo incluindo $\beta_{0}$

- $\quad k-g=$ Numero de parâmetros adicionados sendo testados em $H_{0}$

- $n=$ Tamanho total da amostra

O coeficiente de determinação é igual à soma dos quadrados da regressão (variação explicada pelo modelo de regressão) dividida pela soma total dos quadrados (variação total existente no modelo de regressão). Portanto, o coeficiente de determinação mede a proporção da variação na variável dependente que é explicada pelas variáveis independentes. Valores próximos a \pm 1 indicam uma forte relação linear (LEVINE et al., 2011). Ele é calculado pela seguinte fórmula:

$$
\mathrm{R}^{2}=\frac{\text { Soma dos quadrados da regressão }}{\text { Soma total dos quadrados }}
$$

Este coeficiente pode ser calculado no software Excel pela Função PROJ.LIN. Esta função calcula as estatísticas para a estimação de uma reta que melhor se ajusta aos dados usando o método dos mínimos quadrados. A equação desta reta é descrita em uma matriz como a mostrada na Figura 1, e o coeficiente de determinação é indicado na terceira linha da primeira coluna da mesma. 
Figura 1 - Matriz com as estatísticas de regressão pela função PROJ.LIN

\begin{tabular}{|c|c|c|c|c|c|c|}
\hline 1 & $A$ & 日 & $C$ & D & $E$ & $\mathrm{~F}$ \\
\hline 1 & $\mathrm{ITI} \Pi$ & $\mid T_{\Gamma \mid-1}$ & $\cdots$ & $\mathrm{r} \pi 2$ & $\mathrm{ITI}+1$ & $b$ \\
\hline 2 & SE & $8 \mathrm{e} п 1$ & $\cdots$ & $\mathrm{se} 2$ & $8 \mathrm{E}_{1}$ & $\mathrm{SE}$ \\
\hline 3 & 12 & $\mathrm{sev}_{\mathrm{y}}$ & & & & \\
\hline 4 & $F$ & $d_{f}$ & & & & \\
\hline 5 & 3 sreg & spesid & & & & \\
\hline
\end{tabular}

Fonte: Menu de ajuda do Software Excel (2012).

A distribuição F é usada para verificar a validade da hipótese nula. Rejeita-se a mesma se o nível de significância observado ou valor-p for menor do que o nível de significância $(\alpha)$ estabelecido. Normalmente, utiliza-se o valor de $1 \%$ ou $5 \%$ para o nível de significância. $O$ teste consiste na comparação entre o valor de $F_{\text {parcial }}$ e o valor de $F_{\text {tabelado }}$ ou $F_{\alpha, v_{1}, v_{2}}$. Onde:

$$
\begin{aligned}
& \alpha=\text { nivel de significância } \\
& v_{1}=k-g \text { (graus de liberdade do numerador) } \\
& v_{2}=n-(k+1) \text { (graus de liberdade do denominador) }
\end{aligned}
$$

Rejeita-se $H_{0}$ se $F_{\text {parcial }}>F_{\alpha, v_{1}, v_{2}}$.

Com objetivo de esclarecer a notação utilizada neste trabalho. Um experimento fatorial $2^{k}$ com três fatores é apresentado. Nesta situação, tem-se o seguinte modelo completo:

- Fatores: $X_{1} ; X_{2} ; X_{3}$

- Termos de interação de segunda ordem:

$X_{12}$ (Interação entre os fatores 1 e 2); $X_{13}$ (Interação entre os fatores 1 e 3 ); $X_{23}$ (Interação entre os fatores $2 e 3$ );

- Termos de interação de terceira ordem: $X_{123}$ (Interação entre os fatores $1,2 \in 3$ )

- Equação de regressão:

$$
E(y)=\beta_{0}+\underbrace{\beta_{1} X_{1}+\beta_{2} X_{2}+\beta_{3} X_{3}}_{\text {Termos dos efeitos principais }}+\underbrace{\beta_{4} X_{12}+\beta_{5} X_{13}+\beta_{6} X_{23}+}_{\text {Termos dos efeitos de interação }} \underbrace{\beta_{7} X_{123}}_{\text {Termo do efeito de }}
$$


Critérios utilizados na codificação dos níveis:

$\begin{array}{ll}X_{1} & \left\{\begin{array}{l}1 \text { para o primeiro nível } \\ -1 \text { para o segundo nível }\end{array}\right. \\ X_{2} & \left\{\begin{array}{c}1 \text { para o primeiro nível } \\ -1 \text { para o segundo nível }\end{array}\right. \\ X_{3} \quad\left\{\begin{array}{l}1 \text { para o primeiro nível } \\ -1 \text { para o segundo nível }\end{array}\right.\end{array}$

Considerando os critérios expostos e a existência duas replicações este modelo completo pode ser descrito numa planilha eletrônica como demonstrado no Quadro 2.

Quadro 2 - Dados de um experimento fatorial $2^{3}$ completo com 2 réplicas

\begin{tabular}{|c|c|c|c|c|c|c|c|c|}
\hline Resposta & Tratamento & $\mathrm{X} 1$ & $\mathrm{X} 2$ & $\mathrm{X} 3$ & $\mathrm{X} 12$ & $\mathrm{X} 13$ & $\mathrm{X} 23$ & $\mathrm{X} 123$ \\
\hline Valor 1 & 1 & 1 & 1 & 1 & 1 & 1 & 1 & 1 \\
\hline Valor 2 & 2 & 1 & 1 & -1 & 1 & -1 & -1 & -1 \\
\hline Valor 3 & 3 & 1 & -1 & 1 & -1 & 1 & -1 & -1 \\
\hline Valor 4 & 4 & 1 & -1 & -1 & -1 & -1 & 1 & 1 \\
\hline Valor 5 & 5 & -1 & 1 & 1 & -1 & -1 & 1 & -1 \\
\hline Valor 6 & 6 & -1 & 1 & -1 & -1 & 1 & -1 & 1 \\
\hline Valor 7 & 7 & -1 & -1 & 1 & 1 & -1 & -1 & 1 \\
\hline Valor 8 & 8 & -1 & -1 & -1 & 1 & 1 & 1 & -1 \\
\hline Valor 9 & 1 & 1 & 1 & 1 & 1 & 1 & 1 & 1 \\
\hline Valor 10 & 2 & 1 & 1 & -1 & 1 & -1 & -1 & -1 \\
\hline Valor 11 & 3 & 1 & -1 & 1 & -1 & 1 & -1 & -1 \\
\hline Valor 12 & 4 & 1 & -1 & -1 & -1 & -1 & 1 & 1 \\
\hline Valor 13 & 5 & -1 & 1 & 1 & -1 & -1 & 1 & -1 \\
\hline Valor 14 & 6 & -1 & 1 & -1 & -1 & 1 & -1 & 1 \\
\hline Valor 15 & 7 & -1 & -1 & 1 & 1 & -1 & -1 & 1 \\
\hline Valor 16 & 8 & -1 & -1 & -1 & 1 & 1 & 1 & -1 \\
\hline
\end{tabular}

Fonte: Pesquisa dos Autores (2012).

Os termos de interação existentes na planilha mostrada no Quadro 2 são obtidos pela multiplicação das respectivas variáveis $X_{1}, X_{2}$ e $X_{3}$. Por exemplo, o termo de interação $X_{12}$ é obtido pela multiplicação dos termos existentes na coluna de $X_{1}$ pelos termos da coluna de $X_{2}$.

Importante ressaltar a facilidade de interpretação e construção do teste $F_{\text {parcial }}$, uma vez que o mesmo pode ser feito utilizando-se apenas planilhas 
eletrônicas (QUININO; REIS; BESSEGATO, 2013). Isto por sua vez, possibilita que a análise dos dados seja feita com um recurso computacional amplamente utilizado pelas empresas. Assim sendo, isto favorece a difusão do DOE em ambientes que estejam sujeitos às restrições financeiras para a aquisição de Softwares Estatísticos.

\section{O JOGO DA CATAPULTA}

Este jogo não visa apenas o entretenimento, pois trabalha vários conceitos e técnicas estatísticas de planejamento de experimentos. Fisicamente, o jogo consiste numa pequena Catapulta feita de madeira, com articulações, objetos de fixação e gomas elásticas. A construção deste objeto é simples e de baixo custo, sendo inferior a cinquenta reais. A Figura 2 mostra a Catapulta desenvolvida neste trabalho e seus componentes.

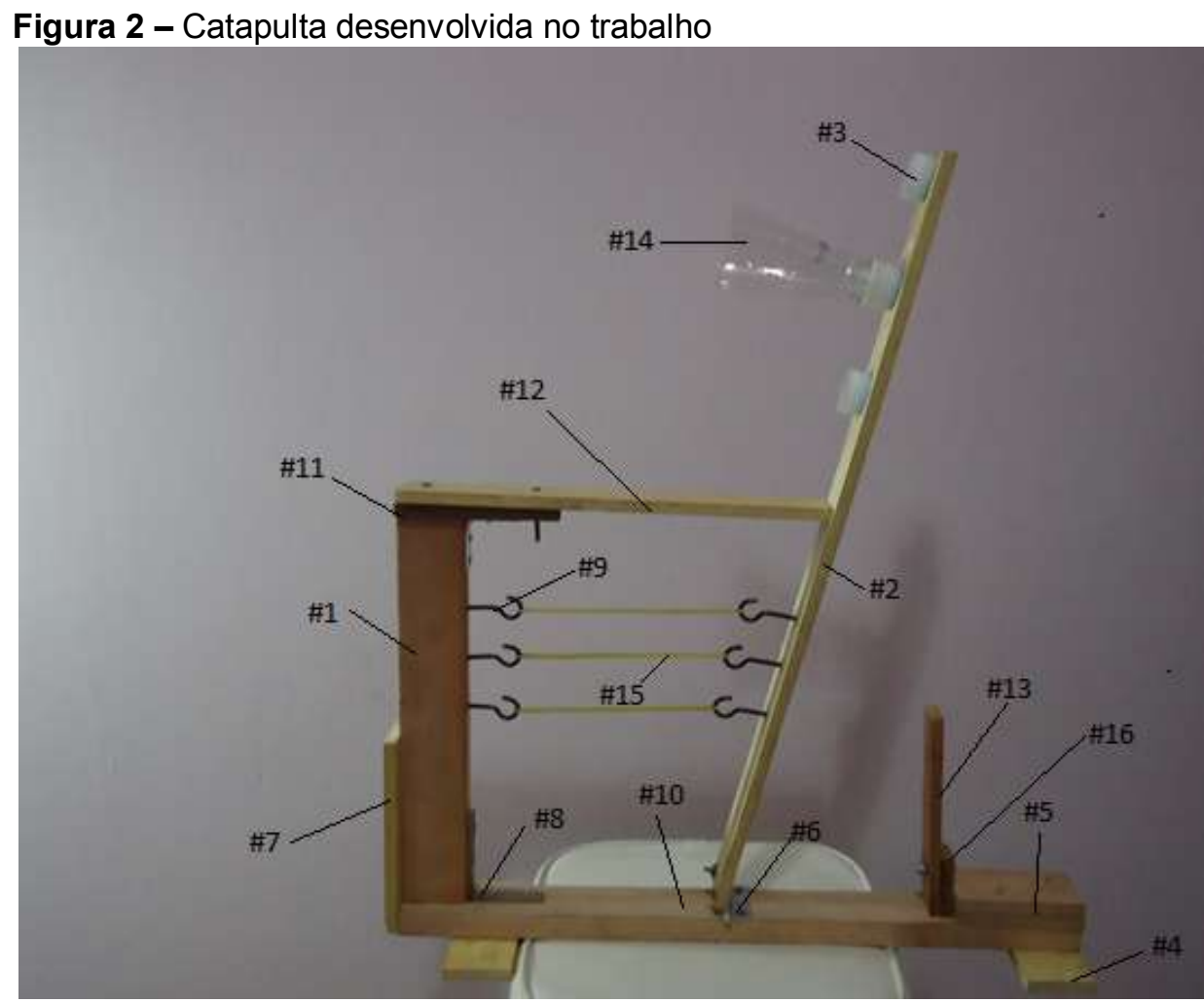

Fonte: Pesquisa dos Autores (2012).

O Quadro 3 faz uma breve descrição dos componentes, identificando sua composição e dimensões. 
Quadro 3 - Descrição dos componentes utilizados para construção da Catapulta

\begin{tabular}{|c|c|c|c|}
\hline Item & Descrição do item & Material e/ou Dimensões & Quantidade \\
\hline \#01 & Base vertical fixa & $\begin{array}{l}\text { Eucalipto } \\
(2 \mathrm{~cm} \times 5 \mathrm{~cm} \times 30 \mathrm{~cm})\end{array}$ & 01 \\
\hline$\# 02$ & Braço de lançamento & $\begin{array}{l}\text { Eucalipto } \\
(1 \mathrm{~cm} \times 5 \mathrm{~cm} \times 56 \mathrm{~cm})\end{array}$ & 01 \\
\hline \#03 & Suporte para o fixador de objetos & $\begin{array}{l}\text { Tampa de plástico de garrafa } \\
\text { pet d'água mineral }\end{array}$ & 03 \\
\hline \#04 & Base de sustentação & $\begin{array}{l}\text { Eucalipto } \\
(1 \mathrm{~cm} \times 5 \mathrm{~cm} \times 13 \mathrm{~cm})\end{array}$ & 02 \\
\hline$\# 05$ & $\begin{array}{l}\text { Base para o encosto vertical do braço de } \\
\text { lançamento }\end{array}$ & $\begin{array}{l}\text { Eucalipto } \\
(2 \mathrm{~cm} \times 5 \mathrm{~cm} \times 9 \mathrm{~cm})\end{array}$ & 01 \\
\hline \#06 & Dobradiça leve para móvel & Latão & 01 \\
\hline$\# 07$ & Reforço para a base verticalfixa & $\begin{array}{l}\text { Eucalipto } \\
(1 \mathrm{~cm} \times 5 \mathrm{~cm} \times 15 \mathrm{~cm})\end{array}$ & 01 \\
\hline$\# 08$ & Cantoneira com abas iguais & Latão & 02 \\
\hline$\# 09$ & Gancho preto para fixação dos elásticos & $\begin{array}{l}50 \mathrm{~mm} \text { de comprimento e } 3 \\
\mathrm{~mm} \text { de diâmetro }\end{array}$ & 06 \\
\hline$\# 10$ & Base fixa horizontal & $\begin{array}{l}\text { Eucalipto } \\
(2 \mathrm{~cm} \times 5 \mathrm{~cm} \times 50 \mathrm{~cm})\end{array}$ & 01 \\
\hline$\# 11$ & $\begin{array}{l}\text { Suporte para o encosto horizontal do braço } \\
\text { de lançado }\end{array}$ & $\begin{array}{l}\text { Eucalipto } \\
(1 \mathrm{~cm} \times 3 \mathrm{~cm} \times 12 \mathrm{~cm})\end{array}$ & 01 \\
\hline$\# 12$ & Encosto horizontal do braço de lançado & $\begin{array}{l}\text { Eucalipto } \\
(2 \mathrm{~cm} \times 5 \mathrm{~cm} \times 18,5 \mathrm{~cm}) \\
(2 \mathrm{~cm} \times 5 \mathrm{~cm} \times 24,5 \mathrm{~cm}) \\
(2 \mathrm{~cm} \times 5 \mathrm{~cm} \times 30,5 \mathrm{~cm})\end{array}$ & 03 \\
\hline$\# 13$ & Encosto vertical do braço de lançamento & $\begin{array}{l}\text { Eucalipto } \\
(1 \mathrm{~cm} \times 5 \mathrm{~cm} \times 11,5 \mathrm{~cm}) \\
(1 \mathrm{~cm} \times 5 \mathrm{~cm} \times 12,5 \mathrm{~cm}) \\
(1 \mathrm{~cm} \times 5 \mathrm{~cm} \times 13,5 \mathrm{~cm})\end{array}$ & 03 \\
\hline \#14 & Apoio para fixar o objeto a ser lançado & $\begin{array}{l}\text { Gargalo de garrafa d'água feito } \\
\text { de pet }\end{array}$ & 01 \\
\hline \#15 & Elásticos & Látex & 03 \\
\hline$\# 16$ & $\begin{array}{l}\text { Base para a fixação do encosto vertical do } \\
\text { braço de lançamento }\end{array}$ & $\begin{array}{l}\text { Eucalipto } \\
(1 \mathrm{~cm} \times 3 \mathrm{~cm} \times 5 \mathrm{~cm})\end{array}$ & 01 \\
\hline
\end{tabular}

Fonte: Pesquisa dos Autores (2012).

A realização deste jogo necessita de certo conhecimento de estatística por parte dos alunos. Estes devem ter domínio acerca de assuntos como teoria de 
probabilidade, distribuições discretas e contínuas, inferências e regressão linear simples e múltipla.

O jogo tem como objetivo arremessar o objeto o mais longe possível. Para tanto, cada grupo de alunos deve planejar vários experimentos trabalhando diferentes ajustes. A catapulta foi concebida de modo a possibilitar ajustes em cinco variáveis. A Figura 3 aponta estas cinco variáveis, possibilitando uma melhor visualização e compreensão das mesmas.

Figura 3 - Catapulta e as diversas variáveis de ajuste

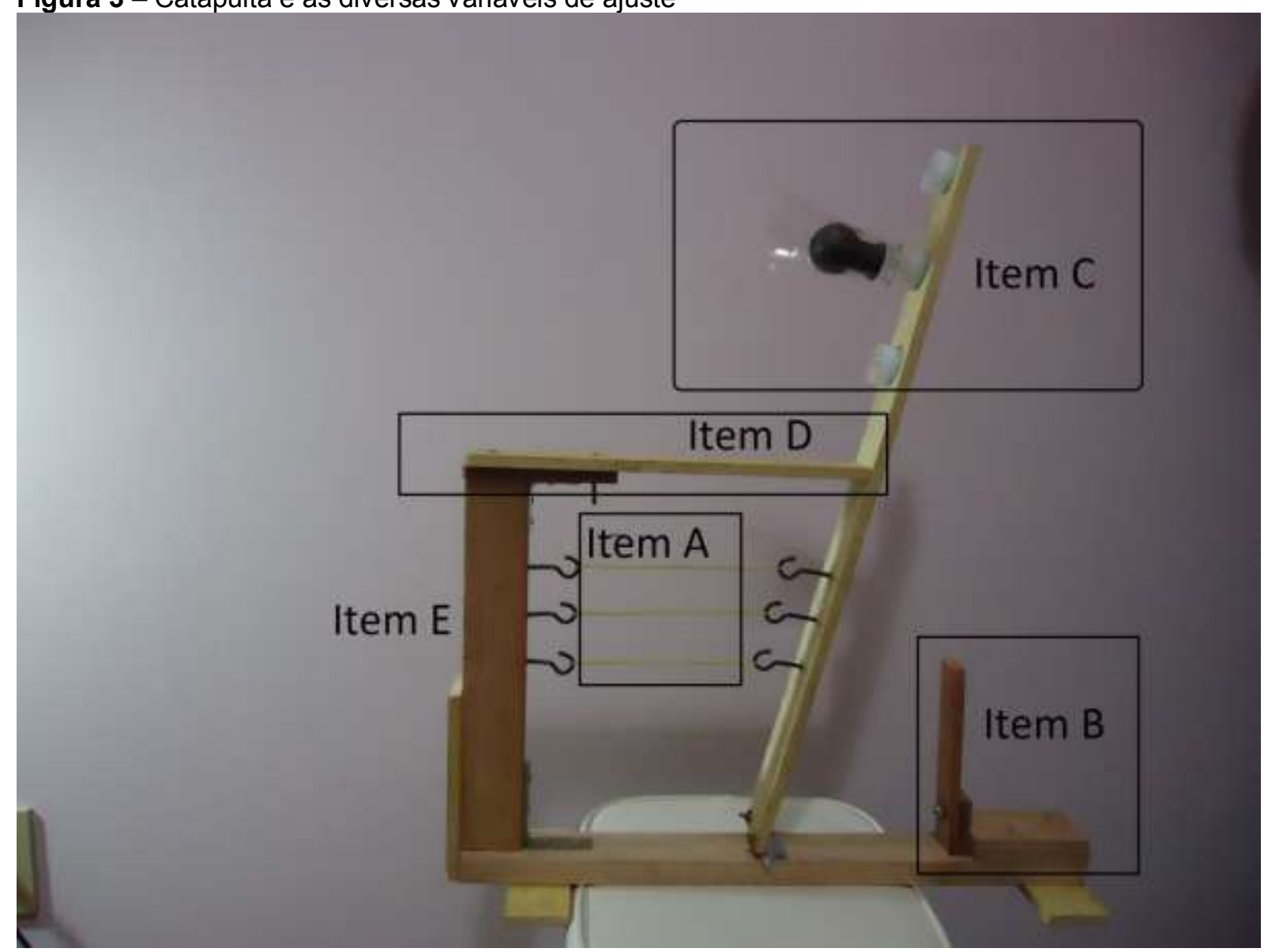

Fonte: Pesquisa dos Autores (2012).

O Quadro 4 ilustra estas variáveis e os respectivos níveis. 
Quadro 4 - Variáveis de ajuste da Catapulta

\begin{tabular}{|l|c|l|}
\hline Variável/Item da Figura 2 & $\begin{array}{l}\text { Níveis } \\
\text { utilizados }\end{array}$ & Descrição \\
\hline Tipo de Elástico (item A) & 2 & $\begin{array}{l}\text { Trabalhou-se com dois tipos de Elástico, um fino } \mathrm{n}^{\circ} 18 \text { e } \\
\text { outro mais grosso. }\end{array}$ \\
\hline Ângulo de arremesso (item B) & 2 & $\begin{array}{l}\text { Definido pela altura do encosto vertical do braço de } \\
\text { lançamento. Esta variável pode assumir diversos níveis. }\end{array}$ \\
\hline $\begin{array}{l}\text { Altura de Lançamento (item C) } \\
\text { Distância do encosto do braço } \\
\text { de lançamento (item D) }\end{array}$ & 3 & $\begin{array}{l}\text { Existem três posições no qual o objeto a ser lançado } \\
\text { pode ser fixado. }\end{array}$ \\
\hline $\begin{array}{l}\text { Quantidade de Elásticos (item } \\
\text { E) }\end{array}$ & 3 & $\begin{array}{l}\text { Definido pelo comprimento do encosto horizontal do } \\
\text { braço de lançado. Esta variável pode assumir diversos } \\
\text { níveis. }\end{array}$ \\
\hline
\end{tabular}

Fonte: Pesquisa dos Autores (2012).

O Jogo da Catapulta também possibilita a compreensão dos diferentes conceitos relacionados ao Planejamento e Análise de Experimentos. Estes podem ser compreendidos mediante confrontação desses com um objeto tangível (Catapulta). A seguir alguns conceitos de DOE são apresentados e contextualizados dentro desta perspectiva:

- $\quad$ Fatores e variáveis respostas: cada processo tem uma multiplicidade de fatores que podem afetar o seu desempenho. Estes fatores e as possíveis variáveis respostas devem ser conhecidos pelos alunos para o projeto de experimentos. No contexto do Jogo da Catapulta, apoiando-se em um diagrama de causa e efeito, os alunos devem analisar a Catapulta para identificar os principais fatores existentes e as possíveis variáveis respostas. A Figura 4 retrata um exemplo de Diagrama de Causa e Efeito deste tipo;

- Unidade experimental refere-se a cada unidade usada no experimento. No contexto do Jogo da Catapulta, cada unidade experimental é um arremesso feito;

- O termo tratamento refere-se ao que se pretende comparar num dado processo. Pode ser máquinas, métodos, parâmetros de processos, 
matérias primas, etc. No contexto do Jogo da Catapulta, o termo tratamento refere-se aos diversos fatores (tipo ou quantidade de elásticos, angulo de arremesso, altura de lançamento, altura do encosto) que podem ser configurados para o arremesso dos objetos;

- Repetiç̃es ou réplicas podem ser entendidas como as unidades experimentais do mesmo grupo, ou seja, que receberam o mesmo tratamento. No contexto do Jogo da Catapulta, as réplicas referem-se aos arremessos que foram configurados com os mesmos parâmetros.

- No contexto do Jogo da Catapulta, o conceito e a importância da casualização podem ser explorados não apenas na fase de projeto do experimento, mas durante a execução do mesmo;

- No contexto do Jogo da Catapulta, o conceito de bloco também pode ser trabalhado, o recipiente que acondiciona o objeto a ser remessado pode ser trabalhado como um bloco, ou o responsável pela medição da distância de arremesso. Neste sentido, dois ou mais tipos de recipientes podem ser utilizados como blocos;

- No contexto do Jogo da Catapulta, o conceito de interação pode ser melhor compreendido após a realização dos experimentos. Neste momento, ao analisar os dados, o aluno poderá constatar a existência de interações entre alguns fatores (VIEIRA, 1999).

Figura 4 - Diagrama de Causa e Efeito para a Catapulta

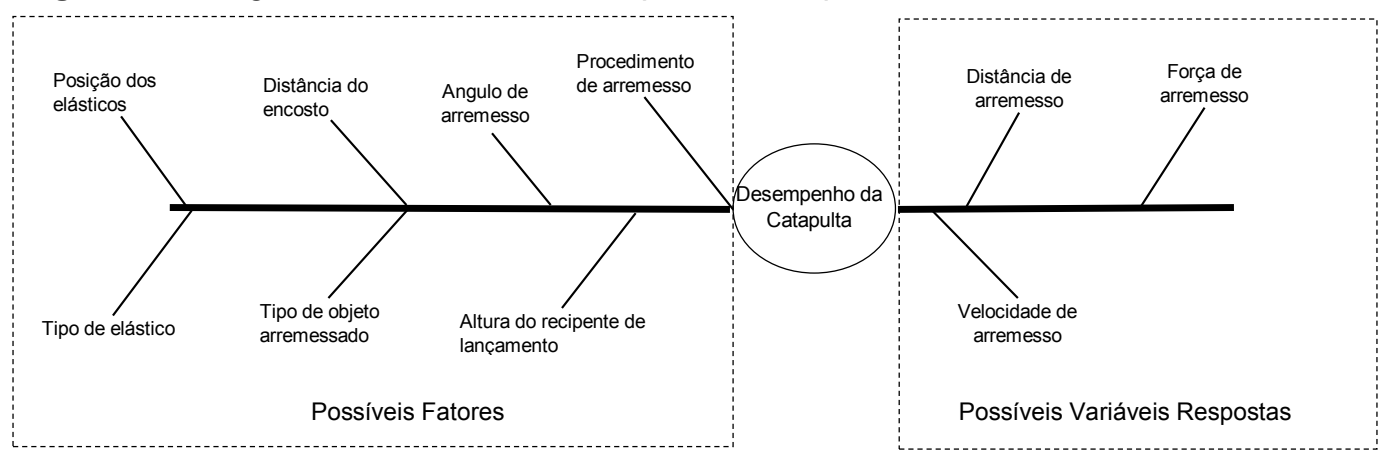

Fonte: Pesquisa dos Autores (2012).

Revista Produção Online, Florianópolis, SC, v.14, n. 3, p. 939-971, jul./set. 2014. 


\subsection{Etapas propostas para o Jogo}

Num primeiro momento, cada grupo deverá selecionar os principais fatores e as possíveis variáveis respostas para a Catapulta. Nesta atividade, eles trabalharão conceitos como unidade experimental, casualização, tratamento, blocagem e réplica no contexto da catapulta.

Posteriormente, cada grupo deverá conduzir um Planejamento Fatorial $2^{5}$ Completo. O experimento realizado neste momento tem um caráter exploratório (screening experiment), visando determinar quais das cinco variáveis de controle são mais importantes para obtenção de uma maior distância de arremesso dos objetos lançados pela Catapulta.

Para este experimento, os alunos deverão preencher os treze itens propostos pelos autores Moen, Nolane Provost (2012) na condução de experimentos. São eles:

1. Objetivo: descrição sintética do objetivo do experimento.

2. Informação anterior: caso o estudo se baseie em experimentos e conhecimentos já adquiridos, este fato deve ser explicitado neste item.

3. Tipo de experimento planejado: descrição do tipo de experimento planejado. Para tanto, o Quadro 1 deste trabalho apresenta uma referência de diversos tipos de experimentos que podem ser utilizados.

4. Variável resposta: descrição da variável observada ou medida no experimento. Um experimento pode apresentar uma ou mais variáveis de resposta.

5. Técnica de medição: descrição do método utilizado para medir a variável de resposta. Este item foi incluso uma vez que poderão existir vários métodos para medir uma mesma resposta.

6. Fatores e níveis utilizados: descrição dos fatores que serão alterados e seus respectivos níveis.

7. Fatores tidos como ruídos no experimento (nuisance factors): descrição de quais fatores conhecidos que perturbam o sistema e podem impactar na variável resposta, mas que não se tem interesse em estudálos. 
8. Método de Controle dos fatores tido como ruídos: descrição do método de controle utilizado para cada ruído. Nesta direção, existem três métodos básicos de controle dos ruídos: i) mantê-los constantes no estudo; ii) medi-los e ajustar seus efeitos na análise de dados; e, finalmente, iii) utilizar a técnica de blocagem.

9. Unidade experimental: descrição da unidade experimental utilizada.

10. Método de aleatorização empregado: descrição do método utilizado.

11. Matriz de dados do experimento: descrição das combinações dos fatores estudados e dos níveis de cada um dos fatores que compõem o experimento fatorial expostos em uma matriz.

12. Análise estatística a ser realizada: descrição dos efeitos que deverão ser analisados e do método que será empregado nesta análise.

13. Estimativa de custo, cronograma e outras considerações de recursos: descrição dos recursos materiais, humanos e financeiros que serão necessários para a execução do experimento.

Após a execução deste experimento, cada grupo deverá entregar um relatório descrevendo as atividades realizadas, os resultados obtidos e as recomendações para que a catapulta consiga atingir uma maior distância no arremesso de objetos.

\section{RESULTADOS ENCONTRADOS}

Com o objetivo de ilustrar o jogo proposto, serão reportados os resultados obtidos em uma experimentação conduzida pelos autores com a Catapulta.

\subsection{O Experimento Fatorial $2^{5}$}

Projetou-se um Experimento Fatorial $2^{5}$ Completo com duas réplicas e um bloco. Este experimento está descrito conforme o framework proposto pelos autores Moen, Nolan e Provost (2012). 
1. Objetivo: compreender como as cinco variáveis investigadas afetam a distância percorrida pelo objeto arremessado pela catapulta.

2. Informação anterior: este experimento é inicial, não existindo dados experimentais anteriores. $\mathrm{O}$ mesmo tem um caráter exploratório (screening experiment).

3. Tipo de experimento planejado: experimento Fatorial $2^{5}$ Completo com duas replicações e apenas um bloco.

4. Variável resposta: distância em centímetros percorrida pelo objeto arremessado pela catapulta.

5. Técnica de medição: será utilizada uma trena. Uma caixa contendo areia marca o ponto em que o objeto arremessado atinge 0 chão. $A$ primeira marca registrada na superfície de areia é o ponto final percorrido pelo objeto. $O$ ponto inicial de referência é a superfície de reforço para a base vertical fixa (Componente \#7).

\section{Fatores e níveis utilizados:}

Quadro 5 - Fatores Utilizados

\begin{tabular}{|l|l|l|l|}
\hline Fator & Tipo de Variável & $\begin{array}{l}\text { Primeiro } \\
\text { Nível }\end{array}$ & $\begin{array}{l}\text { Segundo } \\
\text { Nível }\end{array}$ \\
\hline Tipo de elástico $\left(X_{1}\right)$ & Categórica & Fino & Grosso \\
\hline Ângulo de arremesso $\left(X_{2}\right)$ & $\begin{array}{l}\text { Numérica } \\
\text { Contínua }\end{array}$ & $50^{\circ}$ & $40^{\circ}$ \\
\hline Altura de lançamento $\left(X_{3}\right)$ & Categórica & Baixo & Alto \\
\hline $\begin{array}{l}\text { Distância do encosto da haste de } \\
\text { lançamento }\left(X_{4}\right)\end{array}$ & $\begin{array}{l}\text { Numérica } \\
\text { Contínua }\end{array}$ & $18,5 \mathrm{~cm}$ & $30,5 \mathrm{~cm}$ \\
\hline Quantidade de Elásticos $\left(X_{5}\right)$ & $\begin{array}{l}\text { Numérica } \\
\text { Discreta }\end{array}$ & 2 & 3 \\
\hline
\end{tabular}

Fonte: Pesquisa dos Autores (2012).

7. Fatores tidos como ruídos no experimento (nuisance factors):

a) Pessoa que conduz a medição da variável resposta.

b) Tipo de trena (rígida ou flexível).

c) Formato e peso do objeto lançado. 
8. Método de controle dos fatores tido como ruídos:

a) Pessoa que conduz a medição da variável resposta - manter constante durante todo o experimento - a mesma pessoa deve realizar todas as medições.

b) Tipo de trena (rígida ou flexível) - manter constante durante todo o experimento - utilizar apenas um tipo de trena.

c) Formato e peso do objeto lançado - manter constante durante todo o experimento - utilizar o mesmo objeto em todos os experimentos.

9. Unidade experimental: o arremesso de objeto pela catapulta.

10. Método de aleatorização empregado: números aleatórios gerados pelo programa computacional devem ser utilizados na definição da ordem de execução dos ensaios.

11. Matriz de dados do experimento: esta matriz é apresentada no Quadro 6.

12. Análise estatística a ser realizada: análise dos efeitos dos cinco fatores e dos efeitos das interações de segunda, terceira, quarta e quinta ordem entre os mesmos. O experimento será analisado por meio de Modelos Lineares Gerais (General Linear Models) utilizando o teste F parcial para a verificação da significância dos efeitos.

13. Estimativa de custo, cronograma e outras considerações de recursos: para a realização deste experimento se faz necessário construir uma catapulta como mostrado na Figura 2 e Quadro 6 deste trabalho. O tempo de execução de todos os ensaios é da ordem $60-80$ minutos. 
Quadro 6 - Dados do experimento fatorial $2^{5}$ completo com 2 réplicas

\begin{tabular}{|c|c|c|c|c|c|c|}
\hline \multirow[t]{2}{*}{$\begin{array}{l}\text { Ordem } \\
\text { padrão }\end{array}$} & \multirow[t]{2}{*}{ № de Blocos } & \begin{tabular}{|l|} 
Tipo de \\
Elástico \\
$\left(X_{1}\right.$
\end{tabular} & \begin{tabular}{|l} 
Angulo de \\
arremesso \\
$\left(X_{2}\right)$
\end{tabular} & \begin{tabular}{|l|} 
Altura de \\
Lançamento \\
$\left(X_{2}\right)$
\end{tabular} & \begin{tabular}{|l|} 
Distância do \\
Encosto \\
$\left(X_{4}\right)$
\end{tabular} & $\begin{array}{l}\text { Quantidade } \\
\text { de Elásticos } \\
\left(X_{5}\right)\end{array}$ \\
\hline & & $\left(X_{1)}\right.$ & & & & \\
\hline 1 e 33 & 1 & -1 & -1 & -1 & -1 & -1 \\
\hline 2 e 34 & 1 & 1 & -1 & -1 & -1 & -1 \\
\hline 3 e 35 & 1 & -1 & 1 & -1 & -1 & -1 \\
\hline 4 e 36 & 1 & 1 & 1 & -1 & -1 & -1 \\
\hline 5 e 37 & 1 & -1 & -1 & 1 & -1 & -1 \\
\hline 6 e 38 & 1 & 1 & -1 & 1 & -1 & -1 \\
\hline 7 e 39 & 1 & -1 & 1 & 1 & -1 & -1 \\
\hline 8 e 40 & 1 & 1 & 1 & 1 & -1 & -1 \\
\hline 9 e 41 & 1 & -1 & -1 & -1 & 1 & -1 \\
\hline 10 e 42 & 1 & 1 & -1 & -1 & 1 & -1 \\
\hline 11 e 43 & 1 & -1 & 1 & -1 & 1 & -1 \\
\hline 12 e 44 & 1 & 1 & 1 & -1 & 1 & -1 \\
\hline 13 e 45 & 1 & -1 & -1 & 1 & 1 & -1 \\
\hline 14 e 46 & 1 & 1 & -1 & 1 & 1 & -1 \\
\hline 15 e 47 & 1 & -1 & 1 & 1 & 1 & -1 \\
\hline 16 e 48 & 1 & 1 & 1 & 1 & 1 & -1 \\
\hline 17 e 49 & 1 & -1 & -1 & -1 & -1 & 1 \\
\hline 18 e 50 & 1 & 1 & -1 & -1 & -1 & 1 \\
\hline 19 e 51 & 1 & -1 & 1 & -1 & -1 & 1 \\
\hline 20 e 52 & 1 & 1 & 1 & -1 & -1 & 1 \\
\hline 21 e 53 & 1 & -1 & -1 & 1 & -1 & 1 \\
\hline 22 e 54 & 1 & 1 & -1 & 1 & -1 & 1 \\
\hline 23 e 55 & 1 & -1 & 1 & 1 & -1 & 1 \\
\hline 24 e 56 & 1 & 1 & 1 & 1 & -1 & 1 \\
\hline 25 e 57 & 1 & -1 & -1 & -1 & 1 & 1 \\
\hline 26 e 58 & 1 & 1 & -1 & -1 & 1 & 1 \\
\hline 27 e 59 & 1 & -1 & 1 & -1 & 1 & 1 \\
\hline 28 e 60 & 1 & 1 & 1 & -1 & 1 & 1 \\
\hline 29 e 61 & 1 & -1 & -1 & 1 & 1 & 1 \\
\hline 30 e 62 & 1 & 1 & -1 & 1 & 1 & 1 \\
\hline 31 e 63 & 1 & -1 & 1 & 1 & 1 & 1 \\
\hline 32 e 64 & 1 & 1 & 1 & 1 & 1 & 1 \\
\hline
\end{tabular}

Fonte: Pesquisa dos Autores (2012).

A Tabela 1 mostra os tratamentos realizados e as distancias obtidas(y).

Revista Produção Online, Florianópolis, SC, v.14, n. 3, p. 939-971, jul./set. 2014. 
Tabela 1 - Tratamentos realizados e as distancias de arremesso obtidas (y)

\begin{tabular}{|c|c|c|c|c|c|c|c|c|}
\hline \multirow{2}{*}{ Odempadtāo } & \multirow{2}{*}{ Fr de Bbors } & \multirow{2}{*}{$\begin{array}{c}\text { Trpode } \\
\text { Eltiso } \\
\left(X_{1)}\right.\end{array}$} & \multirow{2}{*}{$\begin{array}{c}\text { Anglo de } \\
\text { arécso } \\
\left(\mathrm{X}_{2}\right)\end{array}$} & \multirow{2}{*}{$\begin{array}{c}\text { Alade } \\
\text { Langa-do } \\
\left(X_{\mathrm{g}}\right)\end{array}$} & \multirow{2}{*}{$\begin{array}{c}\text { Dist do } \\
\text { Enoses } \\
X_{n}\end{array}$} & \multirow{2}{*}{$\begin{array}{c}\text { Qnadade } \\
\text { de Elistions } \\
\left(X_{6}\right)\end{array}$} & \multicolumn{2}{|c|}{$Y(m)$} \\
\hline & & & & & & & 1 & 2 \\
\hline $1 \mathrm{e} 33$ & 1 & -1 & -1 & -1 & -1 & -1 & 65,5 & 63 \\
\hline $2 \mathrm{e} 34$ & 1 & 1 & -1 & -1 & -1 & -1 & 89 & 86 \\
\hline 3 e 35 & 1 & -1 & 1 & -1 & -1 & -1 & 63 & 72 \\
\hline $4 e^{36}$ & 1 & 1 & 1 & -1 & -1 & -1 & 89,5 & 82 \\
\hline $5 e 37$ & 1 & -1 & -1 & 1 & -1 & -1 & 73,5 & 74,5 \\
\hline $6 e^{3}$ & 1 & 1 & -1 & 1 & -1 & -1 & 93 & 96,5 \\
\hline 7eF & 1 & -1 & 1 & 1 & -1 & -1 & 75 & 71,5 \\
\hline $\sec 40$ & 1 & 1 & 1 & 1 & -1 & -1 & 56 & 97 \\
\hline 9e41 & 1 & -1 & -1 & -1 & 1 & -1 & 57,5 & 51,5 \\
\hline $\operatorname{tos} 2$ & 1 & 1 & -1 & -1 & 1 & -1 & 88,5 & 97 \\
\hline 11 e 43 & 1 & -1 & 1 & -1 & 1 & -1 & 62,5 & $\pi$ \\
\hline De 44 & 1 & 1 & 1 & -1 & 1 & -1 & 119 & 108 \\
\hline 13 e 45 & 1 & -1 & -1 & 1 & 1 & -1 & $\pi$ & $\pi, 5$ \\
\hline 14 e 48 & 1 & 1 & -1 & 1 & 1 & -1 & 138 & 125 \\
\hline tse 4 & 1 & -1 & 1 & 1 & 1 & -1 & 99,5 & 87,5 \\
\hline t6e 4 & 1 & 1 & 1 & 1 & 1 & -1 & 143 & 154,5 \\
\hline TeA & 1 & -1 & -1 & -1 & -1 & 1 & 83 & 86,5 \\
\hline tse 50 & 1 & 1 & -1 & -1 & -1 & 1 & 97,5 & 90 \\
\hline Test & 1 & -1 & 1 & -1 & -1 & 1 & 87,5 & 110 \\
\hline Desz & 1 & 1 & 1 & -1 & -1 & 1 & 94,5 & 84,5 \\
\hline 21 e 53 & 1 & -1 & -1 & 1 & -1 & 1 & 85 & 89,5 \\
\hline Ze54 & 1 & 1 & -1 & 1 & -1 & 1 & 109 & 108 \\
\hline ZBe 5 & 1 & -1 & 1 & 1 & -1 & 1 & 93,5 & 91 \\
\hline 24 e 6 & 1 & 1 & 1 & 1 & -1 & 1 & 106 & 102,5 \\
\hline бe⿻ & 1 & -1 & -1 & -1 & 1 & 1 & 92 & 95,5 \\
\hline Be $\mathbf{6}$ & 1 & 1 & -1 & -1 & 1 & 1 & 139 & 149 \\
\hline $\boldsymbol{Z}$ e $\boldsymbol{G}$ & 1 & -1 & 1 & -1 & 1 & 1 & 121,5 & 118 \\
\hline $28+60$ & 1 & 1 & 1 & -1 & 1 & 1 & 163 & 171,5 \\
\hline Ze日 & 1 & -1 & -1 & 1 & 1 & 1 & 100,5 & 134 \\
\hline 30 e 67 & 1 & 1 & -1 & 1 & 1 & 1 & 173 & 173,5 \\
\hline 31 e 63 & 1 & -1 & 1 & 1 & 1 & 1 & 141 & 144,5 \\
\hline 3204 & 1 & 1 & 1 & 1 & 1 & 1 & 205 & 203 \\
\hline
\end{tabular}

Fonte: Pesquisa dos Autores (2012).

A definição do modelo de regressão foi feita pelo método dos melhores subconjuntos. Inicialmente, verificou-se a contribuição dos termos de interação de maior ordem no modelo. Portanto, no modelo reduzido retirou-se o termo que continha a interação de $5^{\circ}$ ordem.

- Modelo Completo: $(y)=\beta_{0}+\left(\beta_{1} x_{1}+\beta_{2} x_{2}+\beta_{3} x_{3}+\beta_{4} x_{4}+\beta_{5} x_{5}\right)+$ Termos principais onde $X_{i}$ significa o fator $X_{i}$

$$
\left(\beta_{6} X_{12}+\beta_{7} X_{13}+\beta_{8} X_{14}+\beta_{9} X_{15}+\beta_{10} X_{23}+\beta_{11} X_{24}+\beta_{12} X_{25}+\beta_{13} X_{34}+\beta_{14} X_{35}+\beta_{15} X_{45}\right)+
$$

Termos com interação de segunda ordem onde $X_{i j}$ significa a interação entre o fator $X_{i}$ e o fator $X_{j}$

Revista Produção Online, Florianópolis, SC, v.14, n. 3, p. 939-971, jul./set. 2014. 
$\underline{\left(\beta_{16} X_{123}+\beta_{17} X_{124}+\beta_{18} X_{125}+\beta_{19} X_{134}+\beta_{20} X_{135}+\beta_{21} X_{145}+\beta_{22} X_{234}+\beta_{23} X_{235}+\beta_{24} X_{245}+\right.}$ $\left.\beta_{25} X_{345}\right)$

Termos com interação de terceira ordem onde $X_{i j k}$ significa a interação entre o fator $X_{i}$, o fator $X_{j}$ e o fator $X_{k}$

$+\left(\beta_{26} X_{1234}+\beta_{27} X_{1235}+\beta_{28} X_{1245}+\beta_{29} X_{1345}+\beta_{30} X_{2345}\right)+$

Termos com interação de quarta ordem onde $X_{i j k\rfloor}$ significa a interação entre o fator $X_{i}$, o fator $X_{j}$, o fator $X_{k}$ e o fator $X_{4}$

$\beta_{31} X_{12345}$

Termos com interação de quinta ordem onde $X_{i j k ! m}$ significa a interação entre o fator $X_{i}$, o fator $X_{j}$, o fator $X_{k^{\prime}}$ o fator $X_{1}$ e o fator $X_{m}$

- Modelo Reduzido: $(y)=\beta_{0}+\left(\beta_{1} X_{1}+\beta_{2} X_{2}+\beta_{3} X_{3}+\beta_{4} X_{4}+\beta_{5} X_{5}\right)+$

$\left(\beta_{6} X_{12}+\beta_{7} X_{13}+\beta_{8} X_{14}+\beta_{9} X_{15}+\beta_{10} X_{23}+\beta_{11} X_{24}+\beta_{12} X_{25}+\beta_{13} X_{34}+\beta_{14} X_{35}+\beta_{15} X_{45}\right)+$

$\left(\beta_{16} X_{123}+\beta_{17} X_{124}+\beta_{18} X_{125}+\beta_{19} X_{134}+\beta_{20} X_{135}+\beta_{21} X_{145}+\beta_{22} X_{234}+\beta_{23} X_{235}+\beta_{24} X_{245}+\right.$

$\left.\beta_{25} X_{345}\right)+\left(\beta_{26} X_{1234}+\beta_{27} X_{1235}+\beta_{28} X_{1245}+\beta_{29} X_{1345}+\beta_{30} X_{2345}\right)$

- $H_{0}: \beta_{31}=0 ;(\mathrm{O}$ termo adicionado não aperfeiçoa significativamente o modelo).

- $H_{1}: \beta_{31} \neq 0 ;(\mathrm{O}$ termo adicionado aperfeiçoa significativamente o modelo).

$F_{\text {parcial }}=\frac{\left(R_{c}^{2}-R_{r}^{2}\right) /(k-g)}{\left(1-R_{c}^{2}\right) /(n-(k+1)]}$

$F_{\text {parcial }}=\frac{(0,98249-0,98231) /(31-30)}{(1-0,98249) /(64-(31+1))}$

$F_{\text {parcial }}=\frac{(0,00017631)}{(0,000547168)}=0,32$

$F_{\alpha, v_{1}, v_{2}}$ onde:

$$
\begin{aligned}
& \alpha=0,05 \\
& v_{1}=k-g=31-30=1 \\
& v_{2}=n-(k+1)=64-(31+1)=32
\end{aligned}
$$

$F_{0.05,1,32}=4,14$

Revista Produção Online, Florianópolis, SC, v.14, n. 3, p. 939-971, jul./set. 2014. 
Como $F_{\text {parcial }}<F_{0.05,1,32}$ não se pode rejeitar $H_{0}$. Portanto o termo $\beta_{31}$ adicionado não aperfeiçoa significativamente o modelo

Uma vez verificada a contribuição do termo de interação de $5^{\circ}$ ordem, será verificada a contribuição dos termos de interação de $4^{\circ}$ ordem ao modelo.

- Modelo Completo: $(y)=\beta_{0}+\left(\beta_{1} X_{1}+\beta_{2} X_{2}+\beta_{3} X_{3}+\beta_{4} X_{4}+\beta_{5} X_{5}\right)+$

$\left(\beta_{6} X_{12}+\beta_{7} X_{13}+\beta_{8} X_{14}+\beta_{9} X_{15}+\beta_{10} X_{23}+\beta_{11} X_{24}+\beta_{12} X_{25}+\beta_{13} X_{34}+\beta_{14} X_{35}+\beta_{15} X_{45}\right)+$

$\left(\beta_{16} X_{123}+\beta_{17} X_{124}+\beta_{18} X_{125}+\beta_{19} X_{134}+\beta_{20} X_{135}+\beta_{21} X_{145}+\beta_{22} X_{234}+\beta_{23} X_{235}+\beta_{24} X_{245}+\right.$ $\left.\beta_{25} X_{345}\right)+\left(\beta_{26} X_{1234}+\beta_{27} X_{1235}+\beta_{28} X_{1245}+\beta_{29} X_{1345}+\beta_{30} X_{2345}\right)$

- Modelo Reduzido: $(y)=\beta_{0}+\left(\beta_{1} X_{1}+\beta_{2} X_{2}+\beta_{3} X_{3}+\beta_{4} X_{4}+\beta_{5} X_{5}\right)+$

$\left(\beta_{6} X_{12}+\beta_{7} X_{13}+\beta_{8} X_{14}+\beta_{9} X_{15}+\beta_{10} X_{23}+\beta_{11} X_{24}+\beta_{12} X_{25}+\beta_{13} X_{34}+\beta_{14} X_{35}+\beta_{15} X_{45}\right)+$

$\left(\beta_{16} X_{123}+\beta_{17} X_{124}+\beta_{18} X_{125}+\beta_{19} X_{134}+\beta_{20} X_{135}+\beta_{21} X_{145}+\beta_{22} X_{234}+\beta_{23} X_{235}+\beta_{24} X_{245}+\right.$ $\left.\beta_{25} X_{345}\right)$

- $H_{0}: \beta_{26}=\beta_{27}=\beta_{28}=\beta_{29}=\beta_{30}=0 ;$ (Termos adicionados não aperfeiçoam significativamente o modelo).

- $H_{1}: \beta_{26} \neq 0 ; \beta_{27} \neq 0 ; \beta_{28} \neq 0 ; \beta_{29} \neq 0 ; \beta_{30} \neq 0$; (Pelo menos um dos termos adicionados aperfeiçoam significativamente o modelo).

$$
\begin{aligned}
& F_{\text {parcial }}=\frac{\left(R_{c}^{2}-R_{r}^{2}\right) /(k-g)}{\left(1-R_{c}^{2}\right) /(n-(k+1)]} \\
& F_{\text {parcial }}=\frac{(0,98231-0,97979) /(30-25)}{(1-0,98231) /(64-(30+1))} \\
& F_{\text {parcial }}=\frac{(0,000503017)}{(0,00053593)}=0,94 \\
& F_{\alpha, v_{1}, v_{2}} \text { onde: }
\end{aligned}
$$

$$
\begin{aligned}
& \alpha=0,05 \\
& v_{1}=k-g=30-25=5 \\
& v_{2}=n-(k+1)=64-(30+1)=33
\end{aligned}
$$

$F_{0.05,5,33}=2,50$

Revista Produção Online, Florianópolis, SC, v.14, n. 3, p. 939-971, jul./set. 2014. 
Como $F_{\text {parcial }}<F_{0.05,5,33}$ não se pode rejeitar $H_{0}$. Portanto, os termos $\beta_{26} ; \beta_{27} ; \beta_{28} ; \beta_{29} ; \beta_{30}$ adicionados não aperfeiçoam significativamente o modelo.

Uma vez verificada a contribuição dos termos de interação de $4^{\circ}$ ordem, será verificada a contribuição dos termos de interação de $3^{\circ}$ ordem ao modelo.

- Modelo Completo: $(y)=\beta_{0}+\left(\beta_{1} X_{1}+\beta_{2} X_{2}+\beta_{3} X_{3}+\beta_{4} X_{4}+\beta_{5} X_{5}\right)+$

$\left(\beta_{6} X_{12}+\beta_{7} X_{13}+\beta_{8} X_{14}+\beta_{9} X_{15}+\beta_{10} X_{23}+\beta_{11} X_{24}+\beta_{12} X_{25}+\beta_{13} X_{34}+\beta_{14} X_{35}+\beta_{15} X_{45}\right)+$

$\left(\beta_{16} X_{123}+\beta_{17} X_{124}+\beta_{18} X_{125}+\beta_{19} X_{134}+\beta_{20} X_{135}+\beta_{21} X_{145}+\beta_{22} X_{234}+\beta_{23} X_{235}+\beta_{24} X_{245}+\right.$ $\left.\beta_{25} X_{345}\right)$

- Modelo Reduzido: $(y)=\beta_{0}+\left(\beta_{1} X_{1}+\beta_{2} X_{2}+\beta_{3} X_{3}+\beta_{4} X_{4}+\beta_{5} X_{5}\right)+$

$\left(\beta_{6} X_{12}+\beta_{7} X_{13}+\beta_{8} X_{14}+\beta_{9} X_{15}+\beta_{10} X_{23}+\beta_{11} X_{24}+\beta_{12} X_{25}+\beta_{13} X_{34}+\beta_{14} X_{35}+\beta_{15} X_{45}\right)$

$-H_{0}: \beta_{16}=\beta_{17}=\beta_{18}=\beta_{19}=\beta_{20}=\beta_{21}=\beta_{22}=\beta_{23}=\beta_{24}=\beta_{25}=0(\mathrm{~T}$

ermos adicionados não aperfeiçoam significativamente o modelo).

$H_{1}: \beta_{16} \neq 0 ; \beta_{17} \neq 0 ; \beta_{18} \neq 0 ; \beta_{19} \neq 0 ; \beta_{20} \neq 0 ; \beta_{21} \neq 0 ; \beta_{22} \neq$

$0 ; \beta_{23} \neq 0 ; \beta_{24} \neq 0 ; \beta_{25} \neq 0$;

(Pelo menos um dos termos adicionados aperfeiçoam significativamente o modelo).

$$
\begin{aligned}
& F_{\text {parcial }}=\frac{\left(R_{c}{ }^{2}-R_{r}^{2}\right) /(k-g)}{\left(1-R_{c}^{2}\right) /(n-(k+1)]} \\
& F_{\text {parcial }}=\frac{(0,97979-0,97197) /(25-15)}{(1-0,97979) /(64-(25+1))} \\
& F_{\text {parcial }}=\frac{(0,000782429)}{(0,000531599)}=1,47 \\
& F_{\alpha, v_{v}, v_{2}} \text { onde: }
\end{aligned}
$$

$$
\begin{aligned}
& \alpha=0,05 \\
& v_{1}=k-g=25-15=10 \\
& v_{2}=n-(k+1)=64-(25+1)=38
\end{aligned}
$$

$F_{0.05,10,38}=2,09$

Revista Produção Online, Florianópolis, SC, v.14, n. 3, p. 939-971, jul./set. 2014. 
Como $F_{\text {parcial }}<F_{0.05,10,38}$ não se pode rejeitar $H_{0}$. Portanto os termos $\beta_{16} ; \beta_{17} ; \beta_{18} ; \beta_{19} ; \beta_{20} ; \beta_{21} ; \beta_{22} ; \beta_{23} ; \beta_{24} ; \beta_{25}$ adicionados não aperfeiçoam significativamente o modelo.

Uma vez verificada a contribuição dos termos de interação de $3^{\circ}$ ordem, será verificada a contribuição dos termos de interação de $2^{\circ}$ ordem ao modelo.

- Modelo Completo: $(y)=\beta_{0}+\left(\beta_{1} X_{1}+\beta_{2} X_{2}+\beta_{3} X_{3}+\beta_{4} X_{4}+\beta_{5} X_{5}\right)+$

$\left(\beta_{6} X_{12}+\beta_{7} X_{13}+\beta_{8} X_{14}+\beta_{9} X_{15}+\beta_{10} X_{23}+\beta_{11} X_{24}+\beta_{12} X_{25}+\beta_{13} X_{34}+\beta_{14} X_{35}+\beta_{15} X_{45}\right)$

- Modelo Reduzido: $(y)=\beta_{0}+\left(\beta_{1} X_{1}+\beta_{2} X_{2}+\beta_{3} X_{3}+\beta_{4} X_{4}+\beta_{5} X_{5}\right)$

$-H_{0}: \beta_{6}=\beta_{7}=\beta_{8}=\beta_{9}=\beta_{10}=\beta_{11}=\beta_{12}=\beta_{13}=\beta_{14}=\beta_{15}=0 ;($ Term os adicionados não aperfeiçoamsignificativamente o modelo).

$H_{1}: \beta_{6} \neq 0 ; \beta_{7} \neq 0 ; \beta_{8} \neq 0 ; \beta_{9} \neq 0 ; \beta_{10} \neq 0 ; \beta_{11} \neq 0 ; \beta_{12} \neq 0 ; \beta_{13} \neq$

$0 ; \beta_{14} \neq 0 ; \beta_{15} \neq 0$;

(Pelo menos um dos termos adicionados aperfeiçoam significativamente o modelo).

$$
\begin{aligned}
& F_{\text {parcial }}=\frac{\left(R_{c}^{2}-R_{r}^{2}\right) /(k-g)}{\left(1-R_{c}^{2}\right) /(n-(k+1)]} \\
& F_{\text {parcial }}=\frac{(0,97197-0,78805) /(15-5)}{(1-0,97197) /(64-(15+1))} \\
& F_{\text {parcial }}=\frac{(0,018392269)}{(0,000583856)}=31,5 \\
& F_{\alpha, v_{1}, v_{2}} \text { onde: }
\end{aligned}
$$

$$
\begin{aligned}
& \alpha=0,05 \\
& v_{1}=k-g=15-5=10 \\
& v_{2}=n-(k+1)=64-(15+1)=48
\end{aligned}
$$

$F_{0.05,10,48}=2,03$

Como $F_{\text {parcial }}>F_{0,05,10,48}$ rejeita-se $H_{0}$. Portanto pelo menos um dos termos $\beta_{6} ; \beta_{7} ; \beta_{8} ; \beta_{9} ; \beta_{10} ; \beta_{11} ; \beta_{12} ; \beta_{13} ; \beta_{14} ; \beta_{15} \quad$ adicionados aperfeiçoam significativamente o modelo. 
Uma vez que pelos um dos termos de interação de $2^{\circ}$ ordem são significativos se faz necessário uma análise individual de cada um deles. Apenas os resultados finais destas análises são apresentados no Quadro 7.

Quadro 7 - Teste F parcial para os Termos de ${ }^{\circ}$ ordem.

\begin{tabular}{|l|c|l|c|}
\hline \multicolumn{1}{|c|}{ Hipóteses } & Valor de $F_{\text {parcial }}$ & \multicolumn{1}{|c|}{ Resultado } & Valor de $\beta$ \\
\hline$H_{0}: \beta_{6}=0 ; H_{1}: \beta_{6} \neq 0$ & 0,44 & Não se pode rejeitar $H_{0}$ & 0 \\
\hline$H_{0}: \beta_{7}=0 ; H_{1}: \beta_{7} \neq 0$ & 9,08 & Rejeita $H_{0}$ & 2,48 \\
\hline$H_{0}: \beta_{8}=0 ; H_{1}: \beta_{8} \neq 0$ & 114,62 & Rejeita $H_{0}$ & 8,83 \\
\hline$H_{0}: \beta_{9}=0 ; H_{1}: \beta_{9} \neq 0$ & 1,71 & Não se pode rejeitar $H_{0}$ & 0 \\
\hline$H_{0}: \beta_{10}=0 ; H_{1}: \beta_{10} \neq 0$ & 0,16 & Não se pode rejeitar $H_{0}$ & 0 \\
\hline$H_{0}: \beta_{11}=0 ; H_{1}: \beta_{11} \neq 0$ & 36,08 & Rejeita $H_{0}$ & 4,95 \\
\hline$H_{0}: \beta_{12}=0 ; H_{1}: \beta_{12} \neq 0$ & 2,36 & Não se pode rejeitar $H_{0}$ & 0 \\
\hline$H_{0}: \beta_{13}=0 ; H_{1}: \beta_{13} \neq 0$ & 45,25 & Rejeita $H_{0}$ & 5,55 \\
\hline$H_{0}: \beta_{14}=0 ; H_{1}: \beta_{14} \neq 0$ & 0,22 & Não se pode rejeitar $H_{0}$ & 0 \\
\hline$H_{0}: \beta_{15}=0 ; H_{1}: \beta_{15} \neq 0$ & 105,09 & Rejeita $H_{0}$ & 8,45 \\
\hline
\end{tabular}

Fonte: Pesquisa dos Autores (2012).

A despeito de vários termos com interação de segunda ordem serem significativos, implicando na significância dos termos de primeira ordem, uma análise individual de cada um deles foi realizada e apenas os resultados finais destas análises são apresentados no Quadro 8. 
Quadro 8 - Teste F parcial para os Termos de $1^{\circ}$ ordem.

\begin{tabular}{|l|c|l|c|}
\hline \multicolumn{1}{|c|}{ Hipóteses } & Valor de $F_{\text {parcial }}$ & \multicolumn{1}{|c|}{ Resultado } & Valor de $\beta$ \\
\hline$H_{0}: \beta_{1}=0 ; H_{1}: \beta_{1} \neq 0$ & 390,61 & Rejeita $H_{0}$ & 16,3 \\
\hline$H_{0}: \beta_{2}=0 ; H_{1}: \beta_{2} \neq 0$ & 47,84 & Rejeita $H_{0}$ & 5,70 \\
\hline$H_{0}: \beta_{3}=0 ; H_{1}: \beta_{3} \neq 0$ & 127,12 & Rejeita $H_{0}$ & 9,30 \\
\hline$H_{0}: \beta_{4}=0 ; H_{1}: \beta_{4} \neq 0$ & 425,82 & Rejeita $H_{0}$ & 17,0 \\
\hline$H_{0}: \beta_{5}=0 ; H_{1}: \beta_{5} \neq 0$ & 358,35 & Rejeita $H_{0}$ & 15,6 \\
\hline
\end{tabular}

Fonte: Pesquisa dos Autores (2012).

Com os resultados mostrados nos Quadros 7 e 8 é possível definir o modelo de regressão para o experimento realizado. Este é apresentado a seguir:

$(y)=\beta_{0}+\beta_{1} X_{1}+\beta_{2} X_{2}+\beta_{3} X_{3}+\beta_{4} X_{4}+\beta_{5} X_{5}+\beta_{7} X_{13}+\beta_{8} X_{14}+\beta_{11} X_{24}+\beta_{13} X_{34}+\beta_{15} X_{45}$

Com o propósito de verificar a adequação do modelo de regressão utilizado, utilizou-se a ferramenta análise de dados disponível no Software Excel. Com esta ferramenta os autores verificaram se os resíduos são independentes, têm média zero, apresentam uma variância constante e estão normalmente distribuídos. Os resultados destas análises são apresentados a seguir.

Tabela 2 - Anova para o modelo de regressão selecionado ANOVA

\begin{tabular}{|c|c|c|c|c|c|}
\hline & $g l$ & $S Q$ & $M Q$ & $F$ & Fde significação \\
\hline Regressão & 10 & $72.230,03$ & $7.223,00$ & 166,34 & 0,0000 \\
\hline Resíduo & 53 & $2.301,45$ & 43,42 & & \\
\hline Total & 63 & $74.531,48$ & & & \\
\hline
\end{tabular}

Fonte: Pesquisa dos Autores (2012)

O baixo nível de significância mostrado pela Anova na Tabela 2 aponta que o modelo de regressão é válido para prever distância de arremesso $(y)$.

O modelo de regressão proposto apresenta um $R^{2}=\frac{72230,03}{74531,48}$ de $96,91 \%$, indicando que aproximadamente $97 \%$ da variação existente na distância de arremesso $(y)$ pode ser explicada pela equação de regressão. 
A Tabela 3, a seguir, reporta uma análise estatística descritiva realizada pela ferramenta análise de dados do Excel com os valores padronizados dos resíduos. Os dados apontam que os resíduos apresentam média e mediana próximas de zero, uma curtose positiva indicando uma concentração ao redor da média e uma assimetria positiva levemente inclinada para a direta.

Tabela 3 - Tratamentos realizados e as distancias de arremessos obtidas

\begin{tabular}{|lr|}
\hline \multicolumn{2}{|c|}{ Resíduos padronizados } \\
\hline \multicolumn{2}{|c|}{} \\
\hline Média & 0,000 \\
\hline Erro padrão & 0,125 \\
\hline Mediana & 0,065 \\
\hline Modo & 1 \\
\hline Desvio padrão & 1 \\
\hline Variância da amostra & 2,32 \\
\hline Curtose & 0,63 \\
\hline Assimetria & 5,96 \\
\hline Intervalo & 2,13 \\
\hline Mínimo & 3,82 \\
\hline Máximo & 0,00 \\
\hline Soma & 64 \\
\hline Contagem & - \\
\hline
\end{tabular}

Fonte: Pesquisa dos Autores (2012).

O Gráfico 1 mostra o gráfico de probabilidade dos resíduos padronizados. Como a maioria dos pontos formam uma reta, pode-se inferir que os resíduos se seguem uma distribuição normal.

Revista Produção Online, Florianópolis, SC, v.14, n. 3, p. 939-971, jul./set. 2014. 
Gráfico 1 - Gráfico de probabilidade dos resíduos padronizados

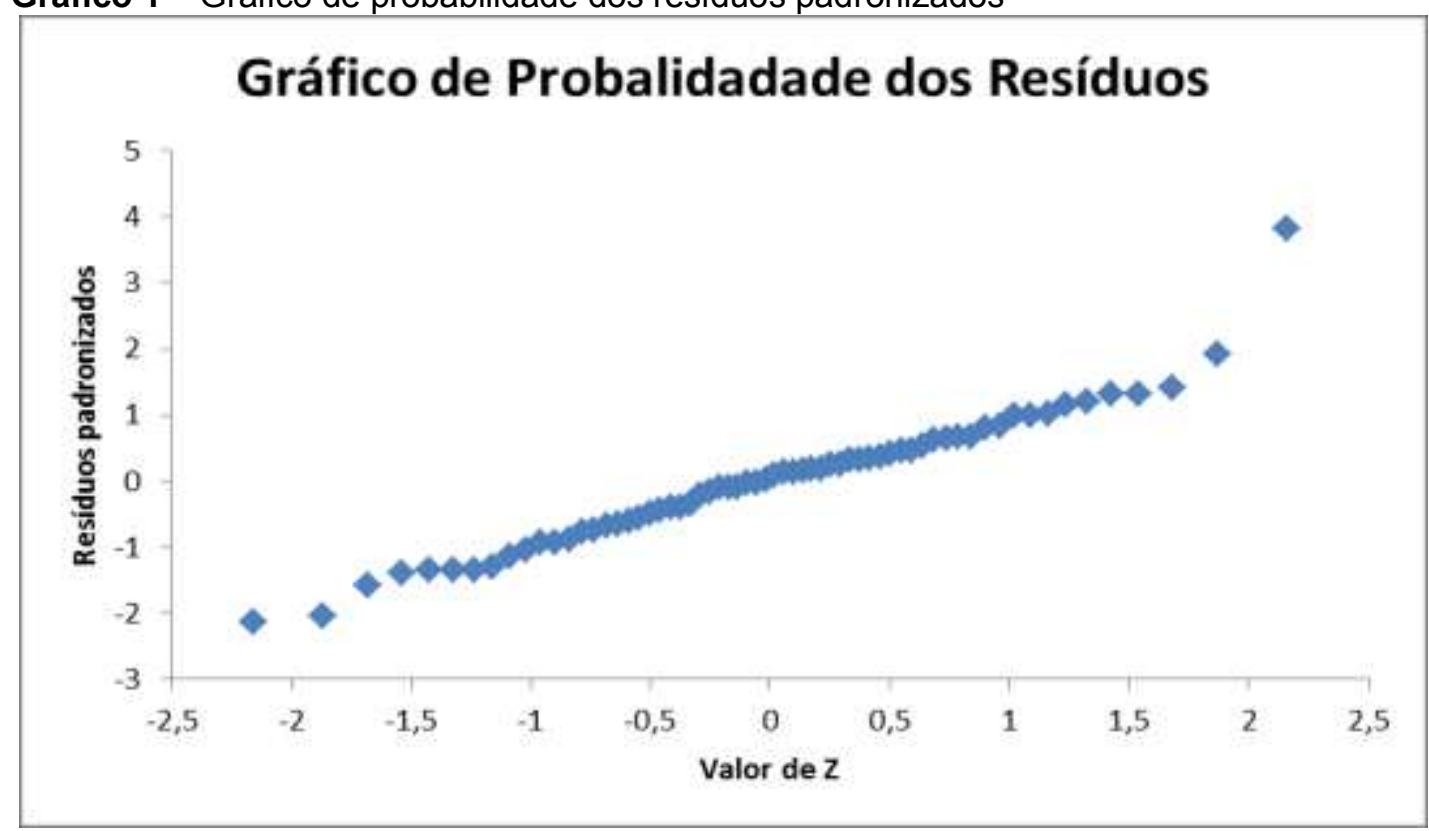

Fonte: Pesquisa dos Autores (2012).

O Gráfico 2 mostra o diagrama de dispersão dos resíduos padronizados por ordem de coleta dos dados. Este indica que os resíduos são independentes e apresentam uma variância constante. Observou-se um valor extremo nos dados coletados.

Gráfico 2- Diagrama de dispersão por ordem de coleta dos resíduos padronizados

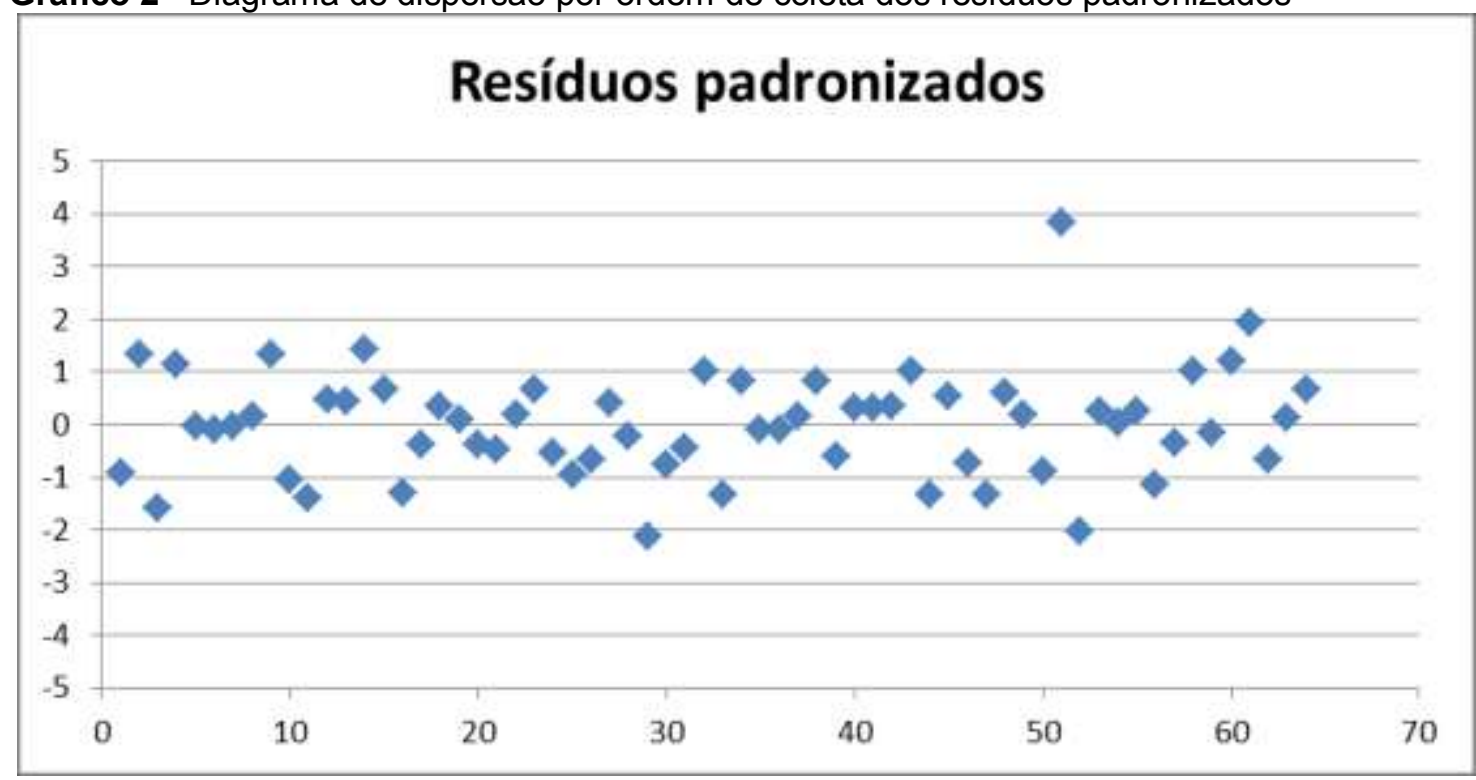

Fonte: Pesquisa dos Autores (2012)

Revista Produção Online, Florianópolis, SC, v.14, n. 3, p. 939-971, jul./set. 2014. 
Pelo exposto anteriormente, pode-se afirmar que o modelo de regressão se mostra adequado para os dados uma vez que os resíduos são independentes, têm média zero, apresentam uma variância constante e estão normalmente distribuídos. Portanto a distância média de arremesso pode ser determinada pela equação de regressão descrita a seguir:

$(y)=105+16,3 X_{1}+5,70 X_{2}+9,30 X_{3}+17 X_{4}+15,6 X_{5}+2,48 X_{13}+8,83 X_{14}+4,95 X_{24}$ $+5,55 X_{34}+8,45 X_{45}$

Considerando o valor obtido pelo Quadrado Médio da Regressão, as três variáveis mais significativas para o modelo são $\mathrm{X}_{4}$ (Distância do encosto da haste de lançamento), $\mathrm{X}_{1}$ (Tipo de Elástico) e $\mathrm{X}_{5}$ (Quantidade de Elásticos) respectivamente.

O ajuste da Catapulta que dá melhor resultado ocorre quando todos os cinco fatores trabalham no nível +1 . A distância de arremesso média estimada para este tratamento é cerca de $199,16 \mathrm{~cm}$.

\section{CONSIDERAÇÕES FINAIS}

Apesar da simplicidade do dispositivo de catapulta, vários cuidados e atividades existentes na condução de experimentos industriais apontadas por Jantony (1999) se fazem presentes neste jogo, uma vez que os condutores dos experimentos realizam várias atividades, são elas:

- Planejar os tratamentos que serão realizados;

- Executar os experimentos respeitando a casualização;

- Uniformizar e definir um procedimento padrão de arremesso;

- Estabelecer um método e definir um instrumento para medição da distância de arremesso;

- Realizar a análise estatística dos dados;

- Elaborar um relatório descrevendo as atividades realizadas, os resultados obtidos e as recomendações para que a catapulta consiga atingir a maior distância no arremesso de objetos. 
Ao considerarmos todas estas atividades existentes no Jogo da Catapulta, este pode ser percebido como um instrumento valioso de aprendizagem da técnica.

Outro aspecto importante na proposta aqui apresentada refere-se ao método de análise utilizado. Os autores optaram pelo uso de Modelos Lineares Gerais (General Linear Models) utilizando o teste $F_{\text {parcial }}$. Na visão dos autores, a regressão pode ser entendida como mais didática que a abordagem convencional de Análise de Variância, pois a regressão trabalha com o conceito de variável dependente e independente, possibilitando uma melhor visualização das relações entre as possíveis causas e o efeito desejado no experimento. Além disso, normalmente, os estudantes da graduação e profissionais da indústria já estão familiarizados com esta ferramenta estatística. Soma-se a estes fatos, a facilidade de interpretação e construção dos modelos de regressão por meio de planilhas eletrônicas. Isto, por sua vez, possibilita que a análise dos dados seja feita sem a necessidade de adquirir e/ou utilizar um Software Estatístico (QUININO; REIS; BESSAGATO, 2013).

Dois pontos podem ser ressaltados como limitações do trabalho.

O primeiro deles refere-se ao fato de que a Catapulta foi construída de tal modo que as variáveis não categóricas como Ângulo de arremesso $\left(\mathrm{X}_{2}\right)$, Altura de lançamento $\left(\mathrm{X}_{3}\right)$ e Distância do encosto da haste de lançamento $\left(\mathrm{X}_{4}\right)$ apresentaram apenas duas opções de valores. Entretanto, caso a Catapulta fosse construída de outra maneira, estas variáveis poderiam ser tratadas como variáveis contínuas. Nessa nova configuração, a possibilidade de ajuste destas três variáveis permitiria a realização de experimentos que utilizassem a metodologia de superfície de resposta. Isto daria ao jogo uma maior flexibilidade para o ensino do DOE.

Como segundo ponto pode-se citar o fato de que os autores TANCO et al. (2009, 2010) argumentam que a eficaz implementação da ferramenta DOE nas organizações se depara com três tipos de barreiras: organizacionais, educacionais e técnicas. A despeito da importância das barreiras organizacionais e técnicas para a efetivação do DOE, o artigo trabalhou apenas barreiras educacionais. 
Para a realização de trabalhos futuros sobre o tema abordado, os autores sugerem a realização de estudos experimentais em disciplinas de DOE na graduação em cursos de engenharia de produção ou afins, onde se verificaria, de maneira precisa, os ganhos para a aprendizagem que a abordagem proposta teria em relação a tradicional.

\section{REFERÊNCIAS}

BARRENTINE, L. B. An Introduction to design of experiments: a simplified approach. Milwaukee: ASQ Quality Press, 1999.

CALADO, V.; MONTGOMERY, D. C. Planejamento de experimentos usando Statistica. Rio de Janeiro: E-Papers serviços Editoriais, 2003.

CARVALHO, M. M.; HOO, L. L.; PINTO, S. H. B. Implementação e difusão do programa Seis Sigma no Brasil, Produção, v. 17, n. 3, p. 486-501, Set./Dez. 2007.

CARVALHO, M. M.; PALADINI, E. P. (coord.) Gestão da Qualidade, Rio de Janeiro: Editora Campus, 2005.

COSTA, N. R.P.; PIRES, A. R.; RIBEIRO, C.O. Guidelines to help practitioners of design of experiments. The TQM Magazine, v. 18, n. 4, p. 386-399, 2006.

http://dx.doi.org/10.1108/09544780610671057

CUPELLO, J. C. Training Technologists in Experimental Design: Consider these seven "best practices" when selecting your next commercial course in experimental design. Research-Technology Management, v. 42, n. 5, p. 47-55, 1999.

DIELMAN, T. E. Applied regression analysis: a second course in Business and Economic Statistics, Mason: Cengage Learning, 4th Edition, 2005.

GALDAMEZ, E. V. C.; CARPINETTI, L. C. R. Aplicação das técnicas de planejamento e análise de experimentos no processo de injeção plástica. Gestão \& Produção, v.11, n.1, p.121-134, jan.-abr. 2004. http://dx.doi.org/10.1590/S0104$\underline{530 \times 2004000100011}$

GALDAMEZ, E. V. C. Aplicação das técnicas de planejamento e análise de experimentos na melhoria da qualidade industrial de um processo de fabricação de produtos plásticos. 2002. 133p. Dissertação (Mestrado) - Escola de Engenharia de São Carlos, São Carlos.

JANTONY, J. Ten useful and practical tips for making your industrial experiments successful. The TQM Magazine, v. 11, n. 4, p. 252-256, 1999.

http://dx.doi.org/10.1108/09544789910272931 
LEVINE, D.M. et al. Estatística: teoria e aplicações usando Microsoft Excel em português. Rio de Janeiro: LTC - Livros Técnicos e Científicos, 2008.

MATHEUS, P. Design of experiments with MINITAB. Milwaukee: ASQ Quality Press, 2005.

MELLO, M. H.; FERREIRA, J. C. E. Avaliação de presença de recursos alternativos em plano de processos para melhorar o desempenho de sistemas manufatura.

Revista Produção Online, v.14, n. 2, p. 648-678, abr./jun. 2014. Disponível em: $<$ http://producaoonline.org.br/rpo/article/view/1467/1149>.

http://dx.doi.org/10.14488/1676-1901.v14i2.1467

MELO, A.; CATEN, C. S.; SANT'ANNA, A. M. O. Otimização dos parâmetros de usinagem na manufatura do ferro fundido. Revista Produção Online, v.13, n. 1, p. 375-388, jan./mar. 2013. Disponível em

http://producaoonline.org.br/rpo/article/view/1200/1000

http://dx.doi.org/10.14488/1676-1901.v13i1.1200

MENDENHALL, W.; SINCICH, T. Second course in statistics:regression analysis. Prentice Hall, 7th Edition, 2012.

MOEN, R.; NOLAN, T.; PROVOST, L. Quality improvement through planned experimentation. third edition, McGraw-Hill Professional, 2012.

MONTGOMERY, D. C. Design and analysis of experiments, 3.ed. New York: John Wiley \& Sons, 1991.

MONTGOMERY, D. C.; RUNGER, G. C. Estatística aplicada e probabilidade para engenheiros. 4. ed. Rio de Janeiro: LTC - Livros Técnicos e Científicos, 2009.

PINTO, S.H.B.; CARVALHO, M. M.; HOO, L. L. Programa seis sigma: aspectos sinérgicos com outras abordagens de gerenciamento da qualidade. Revista Produção Online, v.9, n.1, p. 170-193, mar. de 2009. Disponível em http://www.producaoonline.org.br/index.php/rpo/article/viewFile/203/317 http://dx.doi.org/10.14488/1676-1901.v9i1.203

QUININO, R. C.; REIS, E. A.; BESSEGATO, L. F. Using the coefficient of determination $\mathrm{R}^{2}$ to test the significance of multiple linear regression. TeachingStatistics, v. 35, p. 84-88, 2013. http://dx.doi.org/10.1111/j.14679639.2012.00525.x

RODRIGUES, J. T. M. C.; WERNER, L. Seis Sigma: características do programa em onze empresas situadas na região metropolitana de Porto Alegre. Revista

Produção Online, v.12, n. 1, p. 2-22, jan./mar. 2012. Disponível em http://producaoonline.org.br/rpo/article/view/583/864 http://dx.doi.org/10.14488/1676-1901.v12i1.583 
SOARES, M. H. F. B. Jogos e atividades lúdicas no ensino de química: teoria, métodos e aplicações. In: Departamento de química da UFPR (Org), Anais, XIV Encontro Nacional de Ensino de Química, 2008.

TANCO, M. et al. Barriers faced by engineers when applying design of experiments.

The TQM Journal, v. 21, n. 6, p. 565-575, 2009.

http://dx.doi.org/10.1108/17542730910995846

TANCO, M. et al. Why is not design of experiments widely used by engineers in Europe? Journal of Applied Statistics, v. 37, n. 12, p. 1961-1977, 2010.

http://dx.doi.org/10.1080/02664760903207308

VIANA, D. J.; NETO, A. F. Otimização do processo de fundição sob pressão aplicando o método de Taguchi. Revista Produção Online, v.13, n. 4, p. 1435-1465, out./dez. 2013. Disponível em

http://www.producaoonline.org.br/rpo/article/view/1431/1086

http://dx.doi.org/10.14488/1676-1901.v13i4.1431

VIEIRA, S. Estatística experimental. 2. ed. São Paulo: Atlas, 1999.

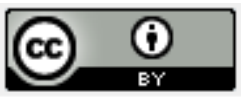

Artigo recebido em 26/04/2013 e aceito para publicação em 22/07/2014

DOI: http://dx.doi.org/ 10.14488/1676-1901.v14i3.1576 